\title{
Minimization of Steady-State Losses in Meshed Networks using VSC HVDC
}

\author{
G. Daelemans, K. Srivastava, Senior Member, IEEE, M. Reza, Member, IEEE, S. Cole, Student \\ Member, IEEE, R. Belmans, Fellow, IEEE
}

\begin{abstract}
The scene of electric power systems has changed drastically and will continue to do so in the years to come. Causes of this evolution are the liberalization of the electricity markets and the increased use of intermittent renewable energy. Uncertainty in the transmitted power and congestion of the lines raise the need for new technologies. High Voltage Direct Current (HVDC) is one of these emerging technologies that may have a major impact, and more specifically Voltage Source Converter (VSC) HVDC. The main part of this paper is to verify the feasibility, technical as well as economic, of VSC HVDC on loss minimization in meshed networks. The losses of the different components of a VSC HVDC link are studied and the impact of the installation on overall system losses in meshed networks is verified through simulations. Simulations are performed on two networks: the small IEEE 14 bus network and the larger IEEE 118 bus network. The networks are investigated in their original state and in a state of increased loading. Finally, an economic analysis is performed to investigate the economic feasibility of VSC HVDC on loss reduction in meshed networks.
\end{abstract}

Index Terms-- Meshed network, optimization, steady-state losses, VSC HVDC.

\section{BACKGROUND}

$\mathrm{T}^{\mathrm{H}}$ HE scene of electric power systems has changed drastically in the last couple of years. Different political, technological and socio-ecological aspects cause this evolution. Throughout Europe, there are two main factors: the liberalization of the electricity markets leading to system unbundling and the interest in renewable energy, especially wind and solar energy, with many large projects planned.

Before the liberalization of the electricity market, each national grid was controlled by a vertically integrated company, often state owned. Power flows in the grid were well known. The centrally coordinated utility was able to control power flows via control of the power plants (active and reactive power), connecting or disconnecting lines,

G. Daelemans is with Elia Engineering, Brussels, Belgium (e-mail: gilles.daelemans@elia-engineering.com).

K. Srivastava is with ABB Corporate Research, Ludvika, Sweden (e-mail: kailash.srivastava@se.abb.com).

M. Reza is with ABB Corporate Research, Ludvika, Sweden (e-mail: muhamad.reza@se.abb.com).

S. Cole is with the Department of Electrical Engineering, Leuven, Belgium (e-mail: stijn.cole@esat.kuleuven.be).

R. Belmans is with the Department of Electrical Engineering, Leuven, Belgium and with Elia, Brussels, Belgium (e-mail: ronnie.belmans@esat.kuleuven.be). changing the tap of tap-changing transformers and inserting capacitor banks for reactive power compensation. The operator had control over both the transmission system and the generators and could give the generators signals to change their operating point. Thus, active and reactive power flows could be controlled by the same company. The connections between the different national grids were built for three main reasons: back-up, stability (maintaining synchronism) and long term contracts between national systems. With the liberalization of the electricity market, generation and transmission are unbundled. Power is contracted bilaterally and traded on power exchange markets. In principle the power flows follow the price differences of the different areas. More power is thus exchanged via the borders of national grids although these lines were not originally built for this purpose. The actual power flows are determined by physical laws however. Because of the limited cross-border transfer capacity between countries, this can lead to congestion of transmission lines.

On the other hand, the increasing use of renewable energy sources raises another problem that transmission system operators have to deal with. Because of the intermittent nature of many renewable energy sources, for example wind and solar, this may lead to unexpected flows in the network. This raises the uncertainty in the transmission grid and can also lead to congestion of the lines.

The challenges of increased and fast changing power flows can be addressed by installing new transmission lines to lighten the load on congested lines. Especially new lines interconnecting different control areas are very interesting. However, installing new overhead lines is difficult because of political and socio-ecological unwillingness. The problem with new overhead lines is their environmental and visual impact. Furthermore there is the concern of electromagnetic fields with the general public.

The previous trends in electric power systems stimulate the search for other alternatives for increasing the use of high voltage overhead lines. New technological developments are getting more attention. An overview of the technical developments in the future transmission grid is presented in [1]. A special group of new technologies are the power flow controlling devices, consisting of phase shifting transformers, Flexible Alternating Current Transmission Systems (FACTS) and HVDC technology [2]. These devices are able to reduce loop flows, lighten bottlenecks and allow the transmission 
system operator (TSO) to operate his grid closer to the limits. Their dynamic behaviour also plays a beneficial role in damping oscillations and the stability of the voltage in the surrounding grid. AC cables on the other hand have no power flow controllability and their losses are higher than comparable overhead lines.

This paper focuses on HVDC, VSC HVDC more specifically. Transmission networks are meshed networks, contrary to distribution networks, that have a radial configuration. The insertion of VSC HVDC in meshed networks is investigated. The last few years, VSC HVDC has become an attractive option for bulk power transport in meshed grids. Advantages are the high controllability of active and reactive power at the converter's terminals and the ability to increase the stability of the surrounding AC system. Active power flow controllability can play an important role in the liberalized electricity market. VSC HVDC has the ability to make contract flows and physical flows equal. Disadvantages of VSC HVDC are the higher losses, the higher cost and the fact that the technology is still fairly new, an aspect that can hold TSO's back from installing a VSC HVDC link. Via the control element in the grid the power flows can be controlled. Several optimisation targets are feasible: minimizing network losses, increasing security margins, increasing cross-border capacity. It has to be stressed that they are far from independent. In this paper the minimization of network losses is studied in particular.

\section{ASPECTS OF VSC HVDC}

\section{A. Overview of VSC HVDC link}

A Voltage Source Converter High-Voltage Direct-Current (VSC HVDC) link consists of two VSC's. These VSC's are connected either directly to each other (back-to-back configuration) or via a high-voltage DC cable (full VSC HVDC) [3]. Active power is transported from the rectifying to the inverting station. A schematic representation of a VSC HVDC link is represented in Figure 1.

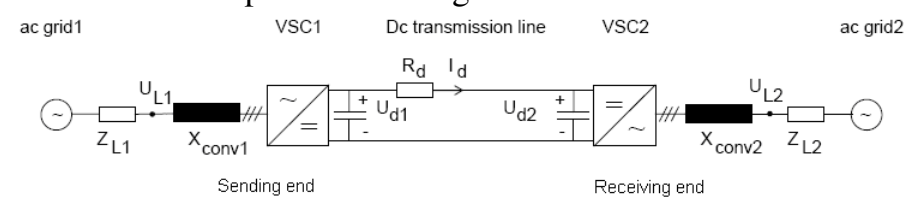

Figure 1: Outlook of VSC HVDC link

Using pulse width modulation, the VSC builds a sinusoidal voltage waveform from the DC voltage. Advantages of VSC HVDC are its high active and reactive power flow controllability. Active power is controlled via the voltage phase angle across the phase reactor and reactive power is controlled via the voltage amplitude across the phase reactor [4]. VSC HVDC can operate in all four quadrants of the active/reactive power plane. Instant power flow reversal is also possible. Disadvantages are its high cost and high losses, mainly due to the voltage source converters. VSC HVDC also has some advantages over the older and more commonly used
Line Commutated Converter (LCC) HVDC technology. LCC converter stations always require reactive power. Power flow reversal with LCC HVDC is slower compared to VSC HVDC. On the other hand, converter station losses with LCC HVDC are lower than VSC HVDC converter station losses.

\section{B. VSC HVDC load flow model}

An existing load flow program [5] is extended to cope with the inclusion of one or more VSC HVDC links [6]. All calculations are performed in Matlab®. A load flow calculation results in the steady-state solution of the network. Using generation, network and load properties, voltages and power flows in the network are obtained using the NewtonRaphson method. The Jacobean matrix, representing the link between voltage and power mismatches, is extended with the VSC HVDC variables. The VSC converters can operate either in reactive power flow control mode, injecting or absorbing a predefined amount of reactive power, or in AC voltage control mode, holding the voltage at the bus connected to the associated converter constant. The number of iterations increases in the extended load flow program compared to the original program.

\section{IMPACT OF VSC HVDC ON LOSSES IN MESHED NETWORKS}

\section{A. Losses of VSC HVDC link}

The losses of an overall VSC HVDC station are the sum of the losses of the individual components. The determination of the loss in every component is given in standards. These standards apply to LCC HVDC converter stations however. More research has to be performed to determine the losses occurring in a VSC HVDC installation. Harmonics are a very important influencing factor in loss calculations. To obtain data on harmonics, field measurements are the best solution. Valve losses are the main contributor to overall VSC HVDC losses. They can be divided in switching and in conduction losses. Switching losses increase linearly with the switching frequency. Conduction losses depend on the threshold voltage and the resistance of the IGBT's and the diodes. Converter losses can be decreased using high-level VSC topologies (two-level vs. three-level) and/or by using optimal pulse width modulation, which cancels certain harmonics. Future developments in semiconductor devices are also taking place. The evolution of converter losses in depicted in Figure 2. 


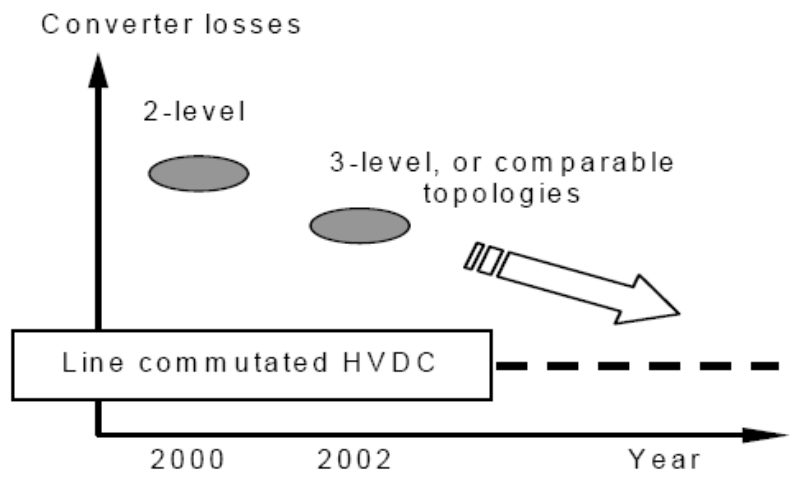

Figure 2: Evolution of converter losses [7]

\section{B. Converter station equivalent loss model}

A typical loss model that takes every component of a VSC HVDC station into account is used. This loss model determines the converter station losses as a function of the active and reactive power exchanged between converter and AC network. Losses can be broken down into three components: no-load losses, losses that depend linearly and quadratically on the phase reactor current $\mathrm{I}_{\mathrm{r}}$. The loss model is for a typical VSC HVDC link with a rating of $600 \mathrm{MW}$ and a DC voltage of $\pm 300 \mathrm{kV}$. The loss model is presented in Table 1.

\begin{tabular}{|c|c|c|}
\hline Constant losses & & \\
\hline Incl. filter, excl. transformer & $5 \mathrm{MW}$ & $0.83 \%$ \\
\hline Transformer load losses & $1.26 \mathrm{MW}$ & $0.21 \%$ \\
\hline Transformer no load losses & $0.36 \mathrm{MW}$ & $0.06 \%$ \\
\hline Current dependent losses & & Nominal condition \\
\hline Linear & $3 \times 600 \mathrm{~V} \mathrm{I}_{\mathrm{r}}$ & $0.30 \%$ (rect) $/ 0.28 \%$ (inv) \\
\hline Square (rectifier) & $3 \times 0.66 \Omega \times \mathrm{I}_{\mathrm{r}}{ }^{2}$ & $0.32 \%$ \\
\hline Square (inverter) & $3 \times 1 \Omega \times \mathrm{I}_{\mathrm{r}}{ }^{2}$ & $0.43 \%$ \\
\hline Total nominal losses (rect) & $\mathbf{1 0 . 3 4} \mathrm{MW}$ & $\mathbf{1 . 7 2 \%}$ \\
\hline Total nominal losses (inv) & $\mathbf{1 0 . 8 6 ~ M W}$ & $\mathbf{1 . 8 1 \%}$ \\
\hline
\end{tabular}

Table 1: Typical VSC HVDC loss model

\section{Advantages of VSC HVDC in meshed networks}

A VSC HVDC connection (including power electronics) between two buses in a network has higher losses than an AC connection between those two buses. Because of the power flow controlling capability of VSC HVDC it is possible to lighten the load on heavily loaded AC lines $\left(P_{\text {loss }} \sim R I^{2}\right)$. The conclusion is that losses in a system consisting of VSC HVDC and a surrounding AC network are globally less than proportional with $\mathrm{RI}^{2}$. Optimization of network losses is thus possible.

Installing a VSC HVDC link in a meshed network can potentially lead to lower network losses. The inclusion of VSC HVDC increases losses but the proper control of active and reactive power can lower network losses. An optimum has to be found, being a minimum in total network losses. Transferring active power over the DC link reduces the load on the lines surrounding the VSC HVDC link. Due to the non-linearity of the system $\left(P_{\text {loss }} \sim R I^{2}\right.$ ), heavily loaded lines contribute more to system losses than lightly loaded lines. VSC HVDC will thus perform better when it is inserted in a heavily loaded network. Loss reduction with LCC HVDC has already been realized with the Fenno-Skan LCC HVDC link [8]. Reactive power can be injected to maintain the voltage at the associated AC bus to a desired value. This is a local problem. Reactive power is used to maintain good voltage profiles. Injecting enough reactive power to achieve good voltage profiles leads to a stable network. Higher voltages lead to lower currents and thus lower losses.

\section{Results of incorporating VSC HVDC in meshed networks}

Simulations are performed on the IEEE 14 and the IEEE 118 bus system. An AC overhead line is replaced by a VSC HVDC link. The VSC HVDC link is installed in a meshed part of the grid and substitutes an "important" AC line which refers to the heaviest loaded AC line. The optimal loading of the VSC HVDC link is searched: power through the DC link minimizing overall network losses.

Reactive power is used to control the voltage at the VSC terminals to a desired value. Both networks are studied in their original state and in a state of increased loading. The results for both systems are comparable. For the IEEE 14 bus system the best result, from a losses point of view, is achieved when replacing the $\mathrm{AC}$ line between buses 1 and 5. When inserting a VSC HVDC link the generators do not reach their reactive power limits so quickly and the overall results are better voltage profiles. This is illustrated in Table 2 .

\begin{tabular}{|c|c|c|c|c|}
\hline Bus & $\begin{array}{c}\text { Voltage original network } \\
\mathbf{3 0} \% \text { increase [pu] }\end{array}$ & $\begin{array}{c}\text { Inj. Q original network } \\
\mathbf{3 0} \% \text { increase [MVAr] }\end{array}$ & $\begin{array}{c}\text { Voltage with VSC HVDC } \\
\mathbf{3 0} \% \text { increase [pu] }\end{array}$ & $\begin{array}{c}\text { Inj. Q with VSC HVDC } \\
\mathbf{3 0 \%} \text { increase [MVAr] }\end{array}$ \\
\hline 1 & 1.06 & 11.35 & 1.06 & -7.55 \\
\hline 2 & 1.029 & 50 (limit) & 1.045 & 45.97 \\
\hline 3 & 0.983 & 40 (limit) & 1.005 & 40 (limit) \\
\hline 5 & 0.993 & - & 1.020 & - \\
\hline 6 & 1.043 & 24 (limit) & 1.070 & 22.80 \\
\hline 8 & 1.069 & 24 (limit) & 1.090 & 22.07 \\
\hline
\end{tabular}

Table 2: Voltage profiles and generator limits with and without VSC HVDC

For each percent of system load increase, the optimal active power over the DC link shifts to higher values. This is illustrated in Figure 3. At higher system loading, VSC HVDC has a greater positive impact. This is presented in Figure 4. In the IEEE 118 bus system, the best result is obtained when the AC overhead lines between buses 25 and 27 and between buses 69 and 75 are replaced. The same conclusions are valid here as in the IEEE 14 bus network, although the effects are less pronounced. 


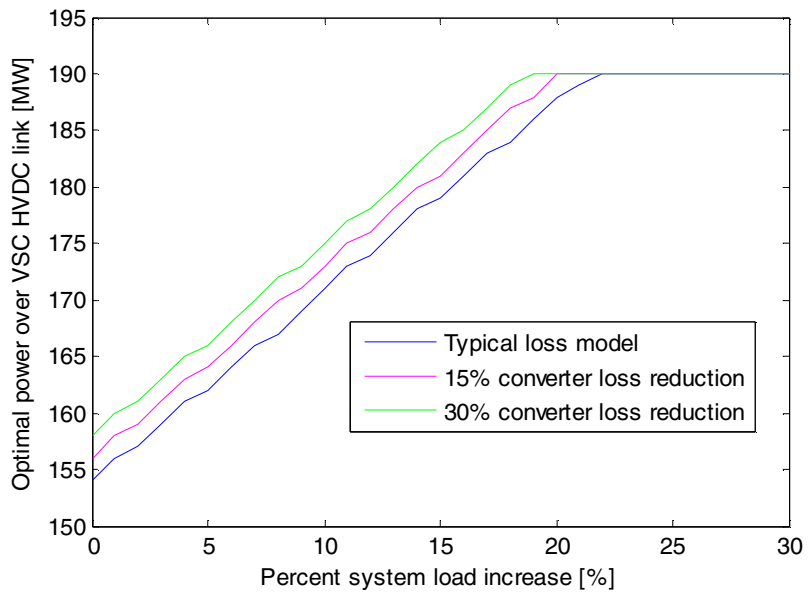

Figure 3: Optimal loading of VSC HVDC link

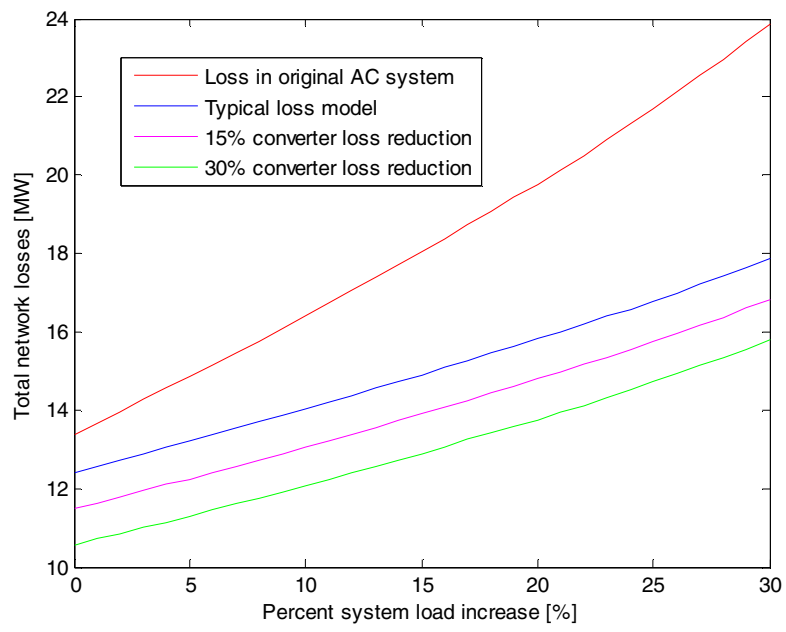

Figure 4: Losses with and without VSC HVDC link

\section{ECONOMIC ANALYSIS}

From the simulations it follows that it is feasible from a technical point of view to reduce losses in a meshed network when an AC overhead line is replaced by a VSC HVDC link. Finally, the economical feasibility is investigated. This is done using a discounted cash flow (DCF) over a period of 30 years, which is typically the lifetime of a VSC HVDC installation. Parameters used are:

- Cost of generating electricity: $40 € / \mathrm{MWh}$ [10]

- Maintenance AC OHL: $1000 € / \mathrm{km} /$ year [11]

- Maintenance VSC HVDC: 0.5\%*capital cost/year [12]

- Converter cost: $40 \mathrm{M€/converter} \mathrm{[13]}$

- DC cable cost: $0.65 \mathrm{M€} / \mathrm{km}[14]+0.03 \mathrm{M€} / \mathrm{km}$ installation cost [15]

Benefits of VSC HVDC that are monetized are the lower losses compared to the original AC line, the availability/utilization of reactive power [9]. Two scenarios are investigated. In the first scenario, the TSO expects a load increase of $1 \%$ of the original load each year. In a second scenario, the TSO expects a sudden load increase, but load varies each year between $0 \%$ and 30\% load increase according to a loading profile. Results are comparable for both scenarios however. In each case $(2$ scenarios and 2 networks: IEEE 14 and IEEE 118) the result of the discounted cash flow is negative: the benefits of VSC HVDC do not outweigh the costs. For the IEEE 14 bus system, the DCF is illustrated in Table 3.

\begin{tabular}{|c|c|c|c|c|}
\hline \multirow{2}{*}{ DCF (SL) } & 0 & 1 & 2 & 3 \\
\hline & $M €$ & M€ & M€ & $M €$ \\
\hline net investment cost & $-94,96$ & & & \\
\hline depreciation & & $-3,16533$ & $-3,16533$ & $-3,16533$ \\
\hline decommissioning AC & 0 & & & \\
\hline energy saving & & 0,392448 & 0,438 & 0,483552 \\
\hline maintenance $\mathrm{AC}$ & & 0,022 & 0,022 & 0,022 \\
\hline maintenance HVDC & & $-0,4748$ & $-0,4748$ & $-0,4748$ \\
\hline voltage support & & 0,505544 & 0,505544 & 0,505544 \\
\hline profit before tax & & $-2,72014$ & $-2,67459$ & $-2,62904$ \\
\hline $\operatorname{tax}$ & & $-1,08806$ & $-1,06984$ & $-1,05161$ \\
\hline profit after tax & & $-1,63208$ & $-1,60475$ & $-1,57742$ \\
\hline depreciation & & 3,165333 & 3,165333 & 3,165333 \\
\hline net cash flow & $-94,96$ & 1,533249 & 1,56058 & 1,587911 \\
\hline discounted cash flow & $-94,96$ & 1,460237 & 1,415492 & 1,371697 \\
\hline TOTAL & $-66,1045$ & & & \\
\hline info & & cost [M€] & & \\
\hline number of converters & 2 & 80 & & \\
\hline length link [km] & 22 & 14,96 & & \\
\hline total [M€] & & 94,96 & & \\
\hline
\end{tabular}

Table 3: Result of DCF

\section{CONCLUSIONS AND DISCUSSIONS}

The feasibility of VSC HVDC on loss reduction in meshed networks has been studied through simulations. The simulations are performed on two networks: the IEEE 14 bus and the IEEE 118 bus network considering both their original state and the state of increased loading.

In both cases, the results obtained demonstrate that the VSC HVDC has a beneficial effect on the losses in the meshed network, which are reduced. Furthermore, the reduction increases with increased system loading. However, the economic analysis shows that the effect is not such that the investment in VSC HVDC can be justified by the loss reduction alone.

The demand for higher controllability in $\mathrm{AC}$ grids and invisible, environmental friendly technologies makes VSC HVDC links an attractive technology for today's already highly constrained $\mathrm{AC}$ grids. In this context, the beneficial effect on losses, particularly at high system loading, contributes to make this technology even more attractive.

\section{REFERENCES}

[1] S. Cole, D. Van Hertem, L. Meeus, R. Belmans, “Technical developments for the future transmission grid," IEEE, International Conference on Future Power Systems 2005. [Online]. Available:

http://www.esat.kuleuven.be/electa/publications/fulltexts/pub_1503.pdf

[2] D. Van Hertem, J. Verboomen, R. Belmans, W. L. Kling, "Power flow controlling devices: An overview of their working principles and their application range," IEEE, International Conference on Future Power Systems 2005. [Online]. Available:

http://www.esat.kuleuven.be/electa/publications/fulltexts/pub_1501.pdf 
[3] G. Asplund, K. Eriksson, K. Svensson, "DC transmission based on Voltage Source Converters," Cigré, Colloquium in South Africa 1997.

[4] P. Haugland, "It's time to connect: Technical description of HVDC Light@ technology," ABB, 2006.

[5] R. D. Zimmerman, Matpower®. [Online]. Available: http://www.pserc.cornell.edu/matpower/

[6] E. Acha, C. R. F. Esquivel, H. A. Perez, C. A. Camacho, "FACTS: Modelling and simulation in power networks," Wiley, first edition, 2004.

[7] B. Andersen, "VSC Transmission," Cigré Working Group B4.37, April 2005.

[8] ABB, "Finland - Sweden submarine interconnection - Fenno-Skan". [Online]. Available: www.abb.com/hvdc

[9] ESB National Grid, "Proposed reactive power payment rates for 2006," 2005. [Online]. Available: http://www.eirgrid.com/EirgridPortal/uploads/Regulation\%20and\%20Prici ng/ESBNG\%20Proposed\%20Reactive\%20Power\%20Payment\%20Rates $\% 20$ for\%202006.pdf

[10] RAENG, "The cost of generating electricity," Royal Academy of Engineering, UK.

[11] REVOLT, "REVOLT news 08/11/2004". [Online]. Available: http://www.revolt.co.uk/news174.html

[12] TGS, "Evaluation of HVDC Light ${ }^{\circledR}$ as an alternative for the Vancouver Island Transmission Reinforcement (VITR) project," 2005. [Online]. Available: http://www.bctc.com/NR/rdonlyres/EFE53841-4E00-4F3EBB7A-C7FEF49444B7/0/VITRAppQ.pdf

[13] Transpower, "North Auckland and Northland grid upgrade project Attachment E: Assessment of options," September 2007. [Online]. Available: http://www.electricitycommission.govt.nz/pdfs/opdev/transmis/gup/naan/P art-III-Attachment-E-Assesment-of-Options.pdf

[14] TREC, "Getting the power to market would entail construction of highvoltage direct current power lines". [Online]. Available: http://www.trec.net.au/content/gettingthepowertomarket.html

[15] D. Ravemark, B. Normark, "Light and invisible; Underground transmission with HVDC Light@,” ABB, ABB Review 4/2005, pp. 25-29, 2005 .

\section{BIOGRAPHIES}

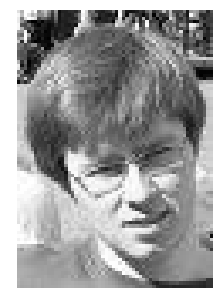

Gilles Daelemans was born in Belgium on 30 march 1985. He received the M.S. degree in electrical engineering in 2008 from the Katholieke Universiteit Leuven in Belgium. He is currently working at Elia Engineering, Belgium.

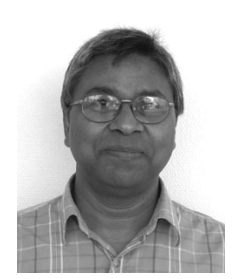

Kailash Srivastava (SM'1996) was born at Fatehpur in India, on October 3, 1962. He graduated in Electrical Engineering from MMM Engineering College Gorakhpur (India) in 1983. He did his MTech and $\mathrm{PhD}$ in Power Systems from IIT Kanpur (India) in 1986 and 1995 respectively. He worked in India and Italy for different companies before joining ABB Corporate Research Sweden where he has been working for past 12 years.

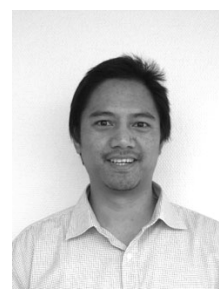

Muhamad Reza (M'2003) was born in Bandung, Indonesia, on 4 November 1974. He obtained his Ph.D in Power Systems from Delft University of Technology, the Netherlands in 2006. Currently he works as research scientist in ABB Corporate Research in Västerås, Sweden, at the Power Technologies Department.

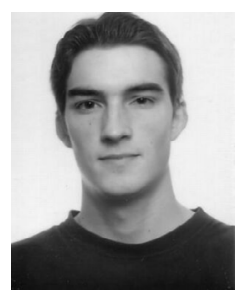

Stijn Cole (SM'05) received the M.S. degree in electrical engineering in 2005 from the Katholieke Universiteit Leuven (K.U.Leuven), Belgium. Since 2005 he is working as a research assistant at K.U.Leuven. He is a member of ELECTA, the Electrical Energy research group, of the department of Electrical Engineering of the K.U.Leuven, where he is working towards a Ph.D. His fields of interest include power systems, grid of the future and HVDC.

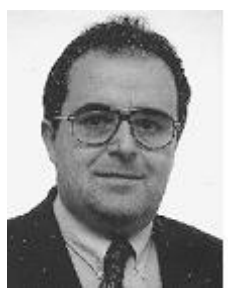

Ronnie Belmans (S'77-M'84-SM'89-F'05) received the M.S. degree in electrical engineering in 1979 and the Ph.D. degree in 1984, both from the K.U.Leuven, Belgium, the Special Doctorate in 1989 and the Habilitierung in 1993, both from the RWTH, Aachen, Germany. Currently, he is a full professor with the K.U.Leuven, teaching electric power and energy systems. His research interests include techno-economic aspects of power systems, power quality and distributed generation. $\mathrm{He}$ is also guest professor at Imperial College of Science, Medicine and Technology, London-UK. Since June 2002 he is chairman of the board of directors of ELIA, the Belgian transmission grid operator. 